\title{
Identification, Evaluation and Treatment of Overweight and Obesity in Adults: Clinical Practice Guidelines of the Obesity Clinic, Wellness Cluster Cipto Mangunkusumo Hospital, Jakarta, Indonesia
}

\author{
Dyah Purnamasari¹, Saptawati Badarsono², Nila Moersadik³, Kartini Sukardji4, \\ Dicky L. Tahapary ${ }^{1}$ \\ ${ }^{1}$ Division of Metabolism and Endocrinology, Department of Medicine, \\ Faculty of Medicine University of Indonesia, Cipto Mangunkusumo Hospital \\ ${ }^{2}$ Department Nutrition, Faculty of Medicine University of Indonesia, Cipto Mangunkusumo Hospital \\ ${ }^{3}$ Department of Sports Medicine, Faculty of Medicine University of Indonesia, Cipto Mangunkusumo Hospital \\ ${ }^{4}$ Diabetes and Lipid Centre, Jakarta
}

\begin{abstract}
Recent surveys have shown that obesity rates are increasing in Indonesia, particularly in urban areas such as the capital city of Jakarta. Cipto Mangunkusumo Hospital, a top referral hospital in Jakarta, established an Obesity Clinic and developed clinical practice guidelines (CPG) for its management. The aim of the CPG was to provide the best evidence-based recommendation for diagnosis, evaluation and multidisciplinary management of overweight and obesity in the adult population. This article summarizes the guidelines.
\end{abstract}

Keywords: obesity, clinical practice guidelines, Indonesia

\section{Introduction}

The prevalence rates of overweight and obesity are increasing rapidly in both developed and developing countries. $^{1-2}$ Previously, overweight and obesity were considered primarily problems of developed countries. However, due to lifestyle changes and urbanization, it is now apparent that developing countries are also faced with the same issues. ${ }^{1-4}$ Policymakers in developing countries have not paid much attention to the problem of excessive weight gain. Obesity contributes to a variety of serious chronic diseases, and thus to a large health burden. Indonesia is a large and populous country and is one of the economically fast growing nations of Asia, and has undergone rapid urbanization including a move of traditional food systems towards a modern supply chain..$^{1-4}$

Recent surveys have shown that obesity rates are also increasing in Indonesia. Based on the National Basic Health Research in 2007, the prevalence of overweight and obesity, as determined by body mass index (BMI), were $8.8 \%$ and $10.3 \%$, respectively. The cumulative prevalence of overweight and obesity was higher in females than in males (23.8\% versus $13.9 \%$ ). Obesity was observed to be more prevalent in urban areas. Furthermore, central obesity, as determined by waist circumference, was

ISSN 0857-1074

Copyright (C) 2011 by the JAFES

Received September 30, 2011. Accepted October 5, 2011. present in $18.8 \%$, and was more commonly observed in females (29\% versus $7.7 \%$ in males) and in urban area dwellers (23.6\% versus $15.7 \%$ in rural areas). ${ }^{3}$

Similarly, the Indonesian Family and Life Survey (IFLS) of the Rand Institute, conducted in 1993, 1997, 2000 and 2007, showed that the mean BMI values among Indonesian adults has notably increased Indonesian women had higher BMIs than men, and the difference of BMIs between genders increased from 1993 onward. Average BMI levels were higher in urban compared to rural areas. However, the rate of increase in BMI over time among rural dwellers was higher compared to urban area residents. Data from the IFLS represented $83 \%$ of Indonesian population; a few remote areas were not included in the survey. ${ }^{1}$

In 2006, we performed an epidemiologic study in Jakarta, the capital city of Indonesia (unpublished data). The survey included 1591 subjects aged 25 to 65 years, of which $41 \%$ were male. The prevalence of obesity and central obesity were $52 \%$ and $53 \%$, respectively. In addition, the prevalence of obesity increased with age in both genders. There was a decreasing trend noted after the age of 60 .

Corresponding author: Dicky L. Tahapary, MD

Division of Metabolism and Endocrinology

Department of Internal Medicine

Faculty of Medicine University of Indonesia

Cipto Mangunkusumo Hospital,

Jakarta - Indonesia

Tel. No.:+62 213907703

E-mail: dickytahapary@gmail.com 
Table 1. The prevalence of obesity based on age group and sex

\begin{tabular}{cccccc}
\hline & $\mathbf{2 5 -}<\mathbf{3 0} \mathbf{y}$ & $\mathbf{3 0 - < 4 0} \mathbf{y}$ & $\mathbf{4 0 - < 5 0} \mathbf{y}$ & $\mathbf{5 0}-<\mathbf{6 0} \mathbf{y}$ & $\mathbf{2 6 0} \mathbf{y}$ \\
\hline Male & $31.6 \%$ & $49.2 \%$ & $67.3 \%$ & $68.7 \%$ & $66.7 \%$ \\
Female & $18.4 \%$ & $\mathbf{2 7 . 7} \%$ & $29.8 \%$ & $35.5 \%$ & $38.5 \%$ \\
\hline
\end{tabular}

\section{Summary of Methodology of Guideline Development}

The guidelines were developed by a multidisciplinary representative group. The Obesity Cluster Team reviewed the Cipto Mangunkusumo guidelines for comprehensiveness and accuracy of interpretation of evidence supporting the recommendations. The guideline development group was able to obtain valuable feedback and suggestions to include additional evidence from the literature and to consider alternative interpretation of data. The participants contributed to and influenced the form of the final guideline, making it a comprehensive report from various geographical origins and medical disciplines.

\section{Summary of Recommendations}

\section{Clinical Evaluation of Overweight and Obese Patients}

Overweight and obesity are known risk factors for cardiovascular disease. They also contributes to the development of other chronic diseases, including diabetes and gallbladder disease. In this high risk population, early detection and prompt management of obesity and related risk factors are important in reducing the overall likelihood for developing disease and attendant social consequences. ${ }^{5-12}$

Information from the clinical interview. Upon seeing an overweight or obese patient, the physician needs to collect basic information related to risk factors and possible target organ complications. This includes investigating how and why the patient became obese, how the patient copes with it , and any previous efforts for weight reduction. The risk factors for developing overweight and obesity are age, history of weight gain, use of medications affecting weight (contraceptive agents, glucocorticoids, antipsychotic drugs), cessation of cigarette smoking, menopause, pregnancy, patterns of food intake and level of physical activity level. These are also affected by psychosocial issues relating to the patient's readiness for weight reduction. ${ }^{12}$

Clinical evaluation. During the initial consultation, the nurse or physician should document vital signs and anthropometric measurements, which include body weight, height, BMI, waist circumference, heart rate, blood pressure and body temperature. ${ }^{12}$

The BMI is calculated by using the body weight $(\mathrm{kg})$ divided by the square of the height (m). Recognizing the observations that the risk for diabetes and hypertension doubles with a BMI of $25 \mathrm{~kg} / \mathrm{m}^{2}$, a task force from the Asia-Oceania group of the International Association for the Study of Obesity has proposed a different classification for obesity in the Asia-Pacific population. Based on this classification, obesity is defined as a BMI of $25 \mathrm{~kg} / \mathrm{m}^{2}$ or higher; high-risk waist circumference is $90 \mathrm{~cm}$ or greater for men, and $80 \mathrm{~cm}$ or greater for women. ${ }^{13-14}$

Table 2. Classification of obesity as recommended by the Asia-Pacific Task Force ${ }^{13}$

Risk of Co-morbidities

\begin{tabular}{|c|c|c|c|}
\hline \multirow[b]{3}{*}{ Classification } & \multicolumn{2}{|c|}{ Risk of Co-morbidities } & \\
\hline & \multirow[b]{2}{*}{$\mathrm{BMI}\left(\mathrm{kg} / \mathrm{m}^{2}\right)$} & \multicolumn{2}{|c|}{ Waist Circumference } \\
\hline & & $\begin{array}{l}<90 \mathrm{~cm} \text { (men) } \\
<80 \text { (women) }\end{array}$ & $\begin{array}{l}\geq 90 \mathrm{~cm} \text { (men) } \\
\geq 80 \text { (women) }\end{array}$ \\
\hline Underweight & $<18.5$ & Low $^{\star}$ & Average \\
\hline $\begin{array}{l}\text { Normal } \\
\text { Overweight }\end{array}$ & $\begin{array}{c}18.5-22.9 \\
\geq 23\end{array}$ & Average & Increased \\
\hline At Risk & $23.0-24.9$ & Increased & Moderate \\
\hline Obese I & 25.0-29.9 & Moderate & Severe \\
\hline Obese II & $\geq 30$ & Severe & Very Severe \\
\hline
\end{tabular}

Laboratory tests. Laboratory tests are performed to exclude other endocrine causes, screen for co-morbidities (e.g. dyslipidemia, impaired glucose tolerance) and other target organ complications, if they are indicated. The most important comorbidity is the metabolic syndrome (MetS), a complex of traits that enhance the risk of cardiovascular disease. MetS includes a variety of conditions such as central obesity, hypertension, insulin resistance, dyslipidemia, and diabetes mellitus. Based on the National Cholesterol Education Program Adult Treatment Panel III (NCEP ATP III) criteria, metabolic syndrome is identified if there are 3 or more of the mentioned conditions present. ${ }^{15}$ Other co-morbidities include family history of early cardiovascular disease, cholecystitis/cholelithiasis, obstructive sleep apnea and osteoarthritis.

Clinical plan. Once the workup for etiologic and complicating factors is complete, the risk associated with elevated BMI, fat distribution, weight gain, and level of physical activity can be evaluated. ${ }^{5-12}$ An early diseaseoriented algorithm was published by Bray et al (Figure 1). ${ }^{12}$ The adapted version of National Heart, Lung and Blood Institute (NHLBI) treatment algorithm for overweight and obesity is presented in Figure 2. ${ }^{10}$

In the primary care setting, there are 10 steps to treating overweight and obesity: ${ }^{12}$

1. Measure height and weight.

2. Measure waist circumference.

3. Assess comorbidities.

4. Should your patient be treated?

5. Is the patient ready and motivated to lose weight?

6. Which diet should you recommend?

7. Discuss a physical activity goal. Discuss a physical activity program.

8. Review the Weekly Food and Activity Diary.

9. Give the patient copies of dietary information and exercise prescription.

10. Enter the patient's information and the goals you have agreed on in the weight and goal record. 


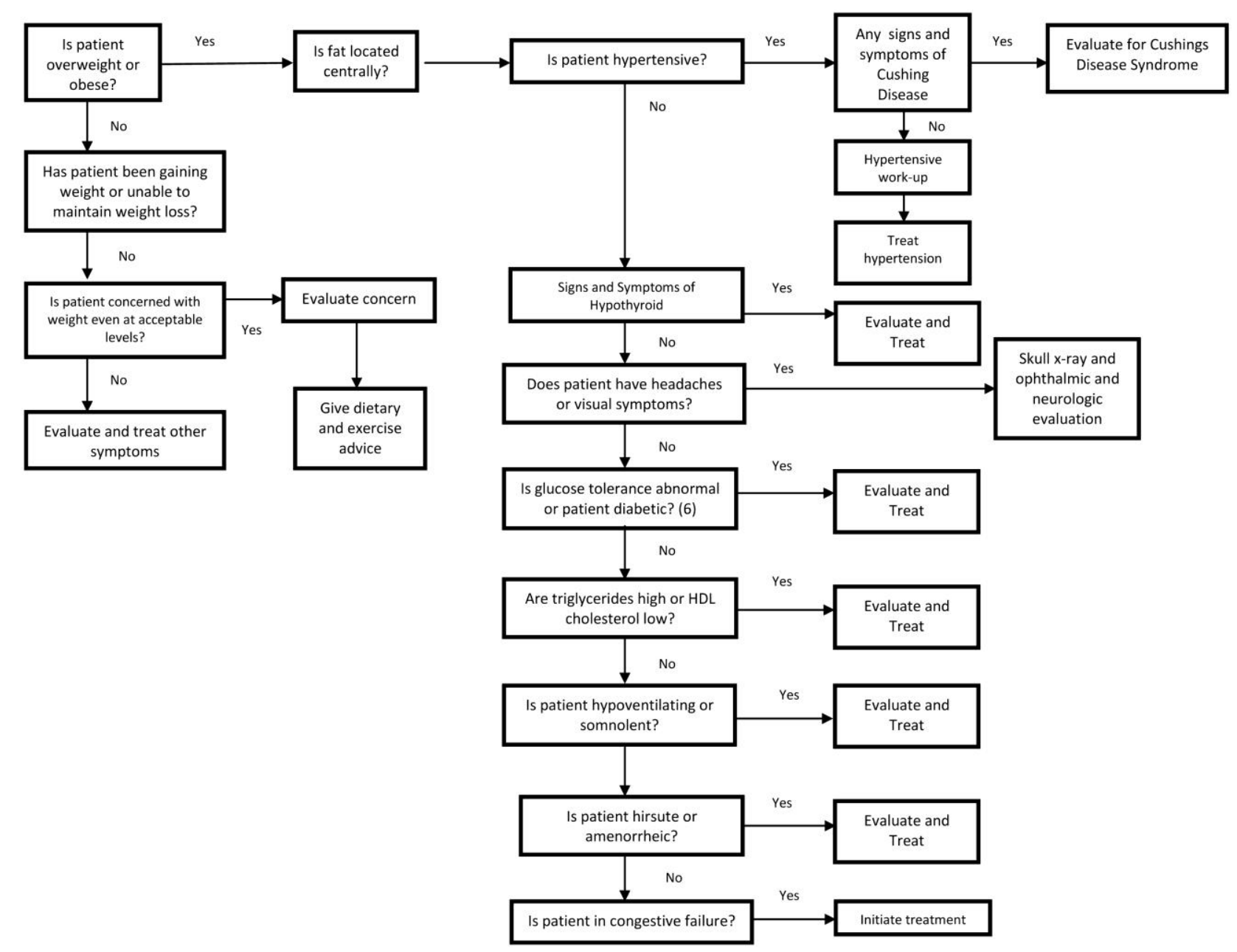

An algorithm for evaluating when laboratory and clinical testing may be needed and for approaching treatment strategies

Figure 1. An algorithm for the appropriate indication for laboratory and clinical testing in the evaluation of the overweight or obese patient. Adapted from: Bray GA. Classification and evaluation of the overweight patient. In: Bray GA, Bouchard C, eds. Handbook of Obesity: Clinical Appications. 2nd ed. 2002. New York: Marcel Dekker, Inc.; 2002:20.

\section{Weight Management Programs and Support for Weight Loss Maintenance in Adults}

In general, among Asians, weight loss therapy is recommended for patients with a BMI of $25 \mathrm{~kg} / \mathrm{m}^{2}$ or greater, and for patients with a BMI between 23 to 24.9 $\mathrm{kg} / \mathrm{m}^{2}$ or a high-risk waist circumference plus two or more risk factors (comorbidities).

The goal of management is to decrease insulin resistance and improve the patient's metabolic profile. The initial goal of weight loss is to reduce baseline weight by $10 \%$ within 6 months, at a rate of approximately 0.5 to $1.0 \mathrm{~kg}(1$ to 2 pounds) per week. After the initial goal is achieved, a weight maintenance program should then be included.

Weight management programs should include lifestyle modification and behavioral management.

\section{Lifestyle Modification}

Lifestyle modification consists of dietary intervention and increased physical activity. Dietary interventions for weight loss should be calculated to reduce 500 to $1000 \mathrm{kcal}$ from the total daily caloric intake. In general, total daily intake may be prescribed at 1000 to $1200 \mathrm{kcal} /$ day for women and 1200 to $1600 \mathrm{kcal} /$ day for men. Programs should be tailored to suit the dietary preferences of the individual patient.

More weight reduction can be achieved by combining dietary restriction and physical activity. Initially, moderate levels of physical activity for 30 to 45 minutes per day, with a frequency of 3 to 5 times per week, may be applied. Overweight and obese individuals should be prescribed a volume of physical activity to expend approximately 1800 to $2500 \mathrm{kcal} /$ week. This corresponds to approximately 225 to 300 minutes in a week of moderate intensity physical activity. This may be achieved through five sessions lasting 45 to 60 minutes each per week, or lesser amounts of vigorous physical activity.

The physical activity program should be tailored according to the individual's health or physical condition. Moderate-intensity cardiovascular exercise for 20 to 60 
minutes (or longer) at least 3 to 5 days per week is recommended initially. Daily exercise, however, is recommended for weight loss. Low-impact activities, such as walking, swimming, water exercise, cycling, and step aerobics are preferred. A strength-training program with 1 to 3 sets of exercises for the major muscle groups, for 10 to 15 repetitions, is recommended at least two days per week. The patient should be advised to start slowly, then gradually increase the frequency, duration and intensity of the exercise. It is important to emphasize adequate fluid intake before, during, and after exercise. The patient should not overdo exercise. ${ }^{16-18}$

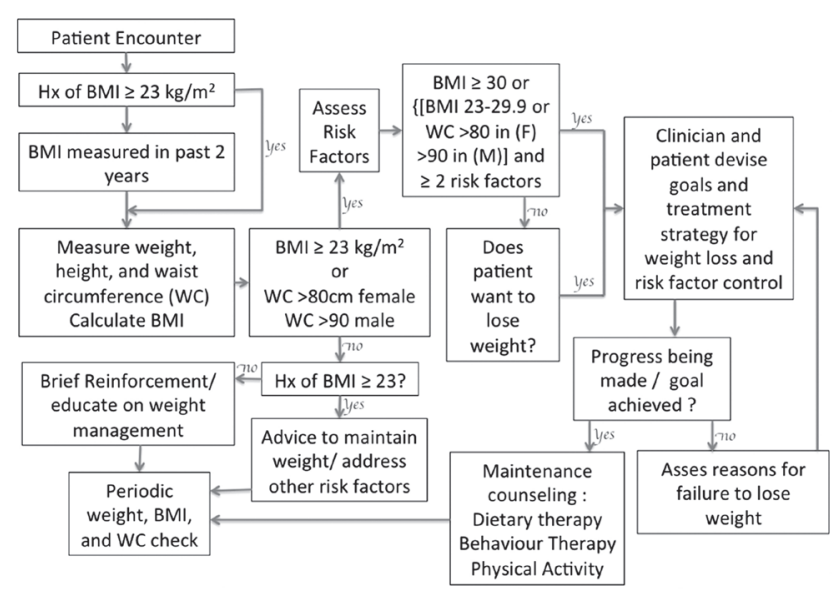

Figure 2. Treatment algorithm of overweight and obesity. The algorithm applies only to the assessment for overweight and obesity and subsequent decisions based on that assessment. It does not reflect the initial general assessment for other cardiovascular risk factors that are indicated. Adapted from: NHLBI Obesity Education Initiative. The Practical Guide: Identification, Evaluation, and Treatment of Overweight and Obesity in Adults. National Insitutes of Health, National Heart, Lung, and Blood Institute; October 2000. NIH Publication No. 004084.

\section{Behavioral modification}

Behavioral modification includes goal setting, self monitoring, stimulus control, cognitive restructuring and prevention of relapse or weight regain.

\section{Pharmacological treatment}

Orlistat should be considered as an adjunct to lifestyle modifications in the management of weight loss. Pharmacologic therapy should be considered on an individual case basis in patients with a BMI of $25 \mathrm{~kg} / \mathrm{m}^{2}$ or greater with co-morbidities, or a BMI of $30 \mathrm{~kg} / \mathrm{m}^{2}$ or greater, following careful assessment of risks and benefits. Medications should never be used without concomitant lifestyle modification.

\section{Surgery}

Bariatric surgery should be included as part of an overall clinical pathway for adult weight management. Bariatric surgery should be considered on an individual case basis following assessment of risks and benefits in patients who fulfill the following criteria: $B M I \geq 35 \mathrm{~kg} / \mathrm{m}^{2}$; presence of one or more severe co-morbidities expected to improve significantly with weight reduction (e.g. severe mobility problems, arthritis, type 2 diabetes); and evidence of completion of a structured weight management program involving diet, physical activity, psychological and drug interventions, not resulting in significant and sustained improvement in co-morbidities.

Table 3. Management strategy in obesity treatment. Adapted from: Institute for Clinical Systems Improvement. Prevention and Management of Obesity (Mature Adolescents and Adults). $5^{\text {th }}$ ed. Bloomington, $\mathrm{MN}$; Institute for Clinical Systems Improvement; April 2011.

\begin{tabular}{lccc}
\hline BMI $\left(\mathbf{k g} / \mathbf{m}^{2}\right)$ & $\mathbf{2 3 . 0 - 2 4 . 9}$ & $\mathbf{2 5 . 0 - 2 9 . 9}$ & $\mathbf{3 0 . 0}$ \\
\hline Risk & Low & Moderate & High \\
Nutrition & $\square$ & $\mathrm{x}$ & $\mathrm{x}$ \\
Physical Activity & $\square$ & $\square$ & $\square$ \\
Behavioral Management & $\square$ & $\square$ & $\square$ \\
Medications & & $\square$ \\
Surgery & & $\mathrm{x}^{*}$ \\
\hline "may be considered if with concomitant obesity-related risk factors or \\
diseases are present and with failure of weight loss after lifestyle
\end{tabular}
modification

\section{Conclusion}

Since not all overweight and obese persons show signs and symptoms of co-morbidities, screening and evaluation is important. The goal of management is to decrease insulin resistance and improve metabolic profile among the obese. The combination of reduced caloric intake, physical activity and behavioral therapy, remains the most effective way of reducing and maintaining weight, preventing obesity-related metabolic disorders and improving cardiorespiratory fitness.

\section{References}

1. Romling C, Qaim M. Direct and Indirect Determinants of Obesity: The Case of Indonesia. Global Food Discussion Papers. GeorgAugust-University of Gottingen. Jun 2011.

2. Usfar AA, Lebenthal E, Atmarita, Achadi E, Soekirman, Hadi H. Obesity as a poverty-related emerging nutrition problems: The case of Indonesia. Obes Rev. 2010;11(12):924-8.

3. Badan Penelitian dan Pengembangan Kesehatan, Departemen Kesehatan Republik Indonesia. Laporan Hasil Riset Kesehatan Dasar (RISKESDAS) Indonesia tahun 2007. 2008. CV Kiat Nusa, Jakarta, Indonesia, 2008.

4. Ramachandran A, Snehalatha C. Rising burden of obesity in Asia. J Obes. 2010.

5. Scottish Intercollegiate Guidelines Network. Management of obesity: A national clinical guideline. Edinburgh: Scottish Intercollegiate Guidelines Network; Feb 2010.

6. Horizon Blue Cross Blue Shield of New Jersey. Clinical Practice Guidelines for adult obesity 2008. New Jersey: 2008.

7. Lau DCW, Douketis JD, Morrison KM, Hramiak IM, Sharma AM, Ur E. 2006 Canadian clinical practice guidelines on the management and prevention of obesity in adults and children. CMAJ. 2007;176(8):S113.

8. National Institute for Health and Clinical Excellence. Obesity: Guidance on the prevention, identification, assessment and management of overweight and obesity in adults and children. London: National Institute for Health and Clinical Excellence; Dec 2006. NICE Clinical Guideline 42. 
9. National Institute of Health. Clinical guidelines on the identification, evaluation, and treatment of overweight and obesity in adults: The evidence report. National Institutes of Health; Sep 1998. NIH Publication No. 98-4083.

10. National Heart, Lung, and Blood Institute. Obesity Education Initiative. The Practical Guide: Identification, Evaluation, and Treatment of Overweight and Obesity in Adults. National Institutes of Health, National Heart, Lung, and Blood Institute; October 2000. NIH Publication No. 00-4084.

11. Institute for Clinical Systems Improvement. Prevention and Management of Obesity (Mature Adolescents and Adults). $5^{\text {th }}$ ed. Bloomington, MN; Institute for Clinical Systems Improvement; April 2011.

12. From: Bray GA. Classification and evaluation of the overweight patient. In: Bray GA, Bouchard C, eds. Handbook of Obesity: Clinical Applications. 2nd ed. 2002. New York: Marcel Dekker, Inc.; 2002:20.

13. International Obesity Task Force. The Asia-Pacific perspective : redefining obesity and its treatment. World Health Organization Western Pacific Region . 2000
14. WHO Expert Consultation. Appropriate body-mass index for Asian populations and its implications for policy and intervention strategies. Lancet. 2004;363:157-63.

15. Third report of the National Cholesterol Education Program (NCEP) expert panel on detection, evaluation, and treatment of high blood cholesterol in adults (Adult Treatment Panel III). Final report. Circulation. 2002; 106: 3143-421

16. Stevens J, Phillips EM, American College of Sports Medicine. Special conditions. In: Stevens J, Phillips EM, eds. ACSM's Exercise is Medicine: A Clinician's Guide to Exercise Prescription. Philadelphia: Lippincott Williams \& Wilkins; 2009:201-2.

17. Exercise while losing weight. Exercise is Medicine website. Cited 2011, September 15. Available from : http://www. exerciseismedicine.org/documents/YPH_LosingWeight.pdf.

18. American College of Sports Medicine, Franklin BA, Whaley $\mathrm{MH}_{\text {, }}$ Howley ET, Balady GJ. Other clinical conditions influencing exercise prescription. In: ACSM's Guidelines for Exercise Testing and Prescription. 7th ed. Lippincott Williams \& Wilkins; 2006:216-9.

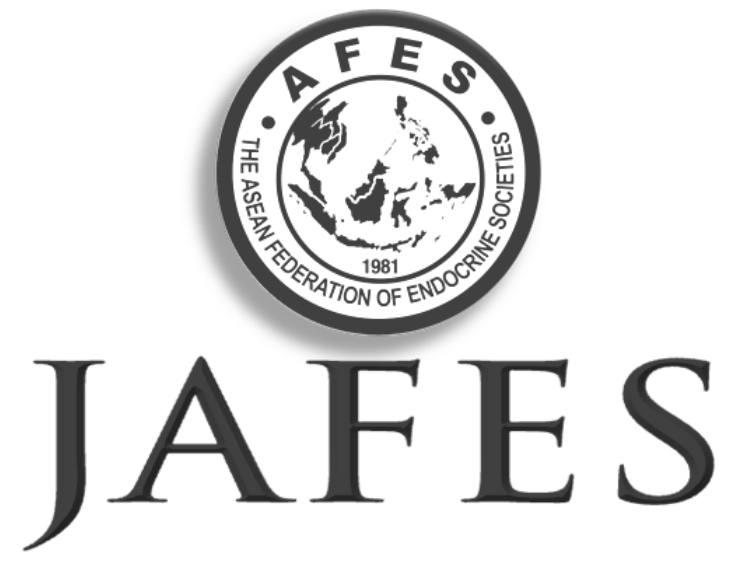

\section{Send your paper to the publication pathway. Instructions to Authors at www.ASEAN-endocrinejournal.org.}

